\title{
Study of risk factors for development of urinary bladder cancer in patients in Urmia; a single-center study by logit regression approach
}

\author{
Rasool Gharaaghaji ${ }^{\circledR}$, Yasamin Pouladi ${ }^{\circledR}$, Ali Tehranchi ${ }^{2^{*}}{ }^{\circledR}$ \\ ${ }^{1}$ Department of Biostatistics and Epidemiology, Urmia University of Medical Sciences, Urmia, Iran \\ ${ }^{2}$ Urology and Nephrology Research Center, Urmia University of Medical Sciences, Urmia, Iran
}

\section{A R T I C L E IN F O}

Article Type:

Original

\section{Article History:}

Received: 9 May 2019

Accepted: 10 September 2019

Published online: 6 October 2019

\section{Keywords:}

Urinary bladder cancer

Genitourinary system

Smoking

Logit model

\begin{abstract}
A B S T R A C T
Introduction: Urinary bladder cancer is the most common genitourinary system malignancy in humans.

Objectives: Due to the high prevalence of urinary bladder cancer, having enough knowledge about urinary bladder cancer risk factors can assist in prevention and early recognition of this malignancy.

Patients and Methods: In this study case-control, 109 individuals with urinary bladder tumor (as a case group) and 200 individuals without any neoplastic history aged $>40$ years (as a control group) were included (2016-2017). The data were collected using patients' files, their pathology reports and also a checklist. The data were analyzed using SPSS version 20, and logistic regression test was applied to investigate the binary outcome. A $P$ value less than 0.05 was considered significant.

Results: The results showed, a significant relationship between smoking $(P<0.001)$, having high risk occupation $(P<0.001)$, low water intake $(P<0.001)$ and pickle consumption $(P<0.001)$ with urinary bladder cancer.

Conclusion: Smoking is a strong risk factor for urinary bladder cancer. Our study showed smoking and other occupational carcinogens are the main causes of urinary bladder cancers. Thus preventing and controlling these risk factors are important for health schedules.
\end{abstract}

Implication for health policy/practice/research/medical education:

According to the results of our study, it seems that the risk factors of cigarette smoking, male gender, high-risk occupation, the use of pickles and low-intake of water are associated with urinary bladder cancer. It should be noted that in our population, the risk of urinary bladder cancer was increased with the increase of smoking and occupational hazards as risk factors.

Please cite this paper as: Gharaaghaji R, Pouladi Y, Tehranchi A. Study of risk factors for development of urinary bladder cancer in patients in Urmia; a single-center study by logit regression approach. J Renal Inj Prev. 2019; 8(4): 306-310. doi: 10.15171/ jrip.2019.56.

\section{Introduction}

Urinary bladder cancer is the most common genitourinary system malignancy, which is accompanied by some symptoms such as hematuria, burning sensation during urination and nocturia (1).

The incidence of urinary bladder cancer is estimated at 5000 cases per year (2). In Iran, urinary bladder cancer is the third most common cancer in men and is the ninth most common cancer in women (3).

A better understanding of the exact etiology of urinary bladder cancer may lead to marked reduction in both the incidence and mortality of this malignancy. However, the cause of urinary bladder cancer is not well-known, while multiple risk factors including tobacco use, occupational exposure to chemicals, schistosomiasis, drugs, urinary tract infection (UTI) and urinary bladder's stones have been identified $(4,5)$.

The risk of urinary bladder cancer is up to four-fold higher among smokers compared with non-smokers. Men are 3-4 times likely to develop urinary bladder cancer than women which is probably due to the increased prevalence of smoking and exposure to environmental carcinogens (6). About $20 \%$ of all urinary bladder cancers are developed due to work exposures such as benzidine-based dyes, aromatic amines, leather, painting, rubber and chemical materials. The risk of urinary bladder cancer after 10 years 
of being exposed to this material drastically increases. In the developed countries due to strict regulations, the incidence of urinary bladder cancer is minimized (7).

To the best of our knowledge, the number of studies carried out on risk factors of urinary bladder cancer in Iran is limited. Compared with other countries, some particular risk factors such as opium use may play an important role in the development of this cancer. The high use of opium and morphine-derived substances in our country has been reported by the United Nations Office on Drugs and Crime (UNODC) in 2008 (8).

\section{Objectives}

Due to the high prevalence of urinary bladder cancer, having enough data about risk factors of this malignancy will assist in prevention and early detection of the disease. Therefore, the authors conducted this study in Urmia to know the etiologies of urinary bladder cancer.

\section{Patients and Methods}

Study population and setting

In this case-control study, 109 individuals with urinary bladder malignancy (as a case group) and 200 patients without any neoplastic history aged more than 40 years (as a control group) were included (2016-2017). The data were collected using patients' files, their pathology reports, using a checklist. The collected data were classified including smoking, drug abuse, body mass index (BMI), history of high-risk occupation (such as truck driving, mechanics, working at metal, leather, textile, petrochemical and aluminum factory, asphalt worker, barber, mining worker and house painter) and low-risk occupation (retired, physician, homeworker, carpetweaver, bakers, clerks, teachers or engineer), diabetes, pickle consumption, recurrent UTI and low water intakes in the two groups.

\section{Ethical issues}

The research followed the tenets of the Declaration of Helsinki. This study was approved by the ethics committee of Urmia University of Medical Sciences (\#IR.UMSU. REC.1394.371). This work has been conducted as part of a medical thesis performed by Yasamin Pouladi in Urmia University of Medical Sciences.

\section{Statistical analysis}

The mean (standard deviation), and chi-square test were used to describe quantitative variables. To compare the means in the two groups, $t$ test was used. The data were analyzed using SPSS version 20, and logistic regression test (using forward method; LR) was used to investigate the binary outcome. Also, the significance level was considered as $P$ value less than 0.05 .

\section{Results}

Statistical analysis of 309 patients showed that the mean age of the cases and control groups were 59.8 and 57.4 years, respectively. There was no statistically significant difference between the case and control groups regarding age. There were 87 patients (79.8\%) with superficial stage of urinary bladder cancer and 22 patients (20.2\%) with muscle invasion. Table 1 shows the distribution of the frequency of gender in the two groups and the odds ratio of developing urinary bladder cancer. The adjusted odds ratio of developing urinary bladder cancer in males was 1.61 more than women. It shows that gender can be considered as a risk factor.

The mean BMI of the case group was more than

Table 1. Odds ratio of the variables (age, occupation, diabetes, Hypertension, BMI and kidney stone) affecting the case and control groups for developing urinary bladder cancer (logistic regression)

\begin{tabular}{|c|c|c|c|c|c|c|}
\hline \multirow{2}{*}{ Variable } & & \multicolumn{2}{|c|}{ Group } & \multirow{2}{*}{ Odds Ratio } & \multirow{2}{*}{$\mathrm{Cl}$} & \multirow{2}{*}{$P$ value } \\
\hline & & Case & Control & & & \\
\hline \multirow{2}{*}{ Gender } & Male & 91 (83.5) & $150(75.8)$ & \multirow{2}{*}{1.61} & \multirow{2}{*}{$0.88-2.95$} & \multirow{2}{*}{0.117} \\
\hline & Female & $18(16.5)$ & $48(24.2)$ & & & \\
\hline \multirow{4}{*}{ BMI $\left(\mathrm{kg} / \mathrm{m}^{2}\right)$} & $20-25$ & $98(49)$ & $44(40.4)$ & 1 & - & - \\
\hline & $<20$ & $10(5)$ & $13(11.9)$ & 2.89 & $1.8-7.10$ & 0.027 \\
\hline & $25-30$ & $74(37)$ & $39(35.8)$ & 1.17 & $0.69-1.98$ & 0.553 \\
\hline & $>30$ & $18(9)$ & $13(11.9)$ & 1.60 & $0.72-3.57$ & 0.241 \\
\hline \multirow{2}{*}{ Occupation } & High risk & $76(69.7)$ & $119(59.5)$ & \multirow{2}{*}{2.30} & \multirow{2}{*}{$1.40-3.77$} & \multirow{2}{*}{0.001} \\
\hline & Low risk & $33(30.3)$ & $81(40.5)$ & & & \\
\hline \multirow{2}{*}{ Diabetes } & Yes & $11(10.1)$ & $14(7)$ & \multirow{2}{*}{1.48} & \multirow{2}{*}{$0.64-3.39$} & \multirow{2}{*}{0.351} \\
\hline & No & 98 (89.9) & $185(93)$ & & & \\
\hline \multirow{2}{*}{ HTN } & Yes & $24(22.2)$ & $54(27.1)$ & \multirow{2}{*}{0.76} & \multirow{2}{*}{$0.44-1.33$} & \multirow{2}{*}{0.343} \\
\hline & No & $84(77.8)$ & 145 (72.9) & & & \\
\hline \multirow{2}{*}{ Kidney stone } & Yes & $7(6.4)$ & $52(26.1)$ & \multirow{2}{*}{0.19} & \multirow{2}{*}{$0.08-0.44$} & \multirow{2}{*}{$<0.001$} \\
\hline & No & 102 (93.6) & 147 (73.9) & & & \\
\hline
\end{tabular}

Abbreviations: BMI, body mass index; HTN, hypertension. 
the control group; however there was no statistically significant difference between the two groups $\left(\chi^{2}=6.32\right.$, $P=0.091)$. In our study, the proportion of patients with history of high-risk occupations in the case group was significantly more than the control group with low-risk occupations (69.7\% versus $59.5 \%$, respectively) and it was statistically significant $(P<0.001)$.

The history of diabetes was slightly in the case group higher $(10.1 \%)$ than the control group $(7 \%)$, but it was not statistically significant $(P=0.351)$. The history of hypertension was lower in the case group than the control group (22.2 versus $27.1 \%$, respectively; $P=0.343$ ). The presence of kidney stones had a significant correlation with the reduction of urinary bladder cancer $(P<0.001$; Table 1). However, this finding requires a more accurate study by deleting the confounding variables.

In relation to drugs used in patients, cardiac, all hypertension and diabetes drugs were compared in two groups and there were not statistically significant. Of the environmental risk factors, cigarette smoking was considered as the most important risk factor for urinary bladder cancer, since following the increase in pocket/year $(\mathrm{p} / \mathrm{y})$ in patients, the risk of urinary bladder cancer increased significantly. Hence, in $\mathrm{p} / \mathrm{y}>21$, it was statistically significant $(P<0.001$; logistic regression test). The consumption of pickles in the case group was higher than the control group ( 81.7 versus $25.6 \%$, respectively; Chi-square test) and significantly increased the odds of urinary bladder cancer $(P<0.001$; logistic regression test). The incidence of UTI was lower in the case group than the control group (22\% versus $34 \%$, respectively; Chisquare test), and it was statistically significant for reducing the odds of urinary bladder cancer $(P=0.027$; logistic regression test). Regarding the intake of fluids, with the increase in the number, the odds ratio was reduced (Table 2).

After univariate analysis, factors that had a significant level of less than 0.1 were introduced into the regression model, and then multivariate analysis was carried out using forward method (LR). The results of logistic regression analysis are presented in Table 3.

\section{Discussion}

Studies on the effects of risk factors such as nutrition, fluid intake, BMI, and diabetes on bladder cancer are few and most of the studies are about the effects of cigarette smoking, drugs and occupations on urinary bladder tumor. A study by Aminian et al in 2014 showed that the effects of the occupation of people, including drivers, road builders and pavements, mechanics and working at plastic industry and petrochemical, and welding had the greatest risk for developing urinary bladder cancer (4).

In this study, the occupation of people was in the two groups including high-risk occupations (such as truck driving, mechanics, working at metal, leather, textile, petrochemical and aluminum factory, asphalt worker, barber may be due to the use of permanent hair dyes, mining worker and house painter) and low-risk occupation (retired, physician, homeworker, carpetweaver, bakers, clerks, teachers, engineer, diabetes, pickle consumption, recurrent UTI and low water intakes). In a meta-analysis the role of occupation such as barber was approved for developing urinary bladder cancer (9).

There was a significant relationship between the high-risk occupations and the risk of urinary bladder malignancy. In the study of Vermeulenetal et al in the Netherlands, the effect of UTI on urinary bladder cancer was considered as a risk factor, and people with a low

Table 2. Odds ratio of the variables (Heart, HTN and diabetes drugs, smoking, fluid intake, UTI and pickle use) affecting the case and control groups for developing urinary bladder cancer (logistic regression)

\begin{tabular}{|c|c|c|c|c|c|c|}
\hline \multirow{2}{*}{ Variable } & & \multicolumn{2}{|c|}{ Group } & \multirow{2}{*}{ Odds Ratio } & \multirow{2}{*}{$\mathrm{Cl}$} & \multirow{2}{*}{$P$ value } \\
\hline & & Case & Control & & & \\
\hline \multirow{2}{*}{ Heart drug } & Yes & $14(12.8)$ & $16(8)$ & \multirow{2}{*}{1.69} & \multirow{2}{*}{$0.79-3.62$} & \multirow{2}{*}{0.171} \\
\hline & No & $95(87.2)$ & $184(92)$ & & & \\
\hline \multirow{2}{*}{ HTN drug } & Yes & $23(21.1)$ & $56(28)$ & 0.68 & \multirow{2}{*}{$0.39-1.19$} & \multirow{2}{*}{0.189} \\
\hline & No & 86 (78.9) & $144(72)$ & 2.89 & & \\
\hline \multirow{2}{*}{ Diabetes drug } & Yes & $10(9.2)$ & $13(65)$ & \multirow{2}{*}{1.45} & \multirow{2}{*}{$0.61-3.43$} & \multirow{2}{*}{0.390} \\
\hline & No & 99 (90.8) & $187(93.5)$ & & & \\
\hline \multirow{4}{*}{ Smoking } & No & $40(36.7)$ & $62(31)$ & 1 & - & - \\
\hline & $P / Y \leq 11$ & $10(9.2)$ & $65(32.5)$ & 0.23 & $0.11-0.51$ & $<0.001$ \\
\hline & $P / Y=11-20$ & $11(10.1)$ & $52(26)$ & 0.32 & $0.15-0.70$ & 0.004 \\
\hline & $P / Y \geq 21$ & $48(64)$ & $21(10.5)$ & 3.54 & $1.85-6.77$ & $<0.001$ \\
\hline \multirow{3}{*}{ Fluid intake (glasses) } & $1-4$ & $20(18.3)$ & $90(45.2)$ & 1 & & - \\
\hline & $5-8$ & $72(66.1)$ & $81(40.7)$ & 4 & 2.24-7.13 & $<0.001$ \\
\hline & $<11$ & $17(15.6)$ & $28(14.1)$ & 2.73 & $1.26-5.92$ & 0.011 \\
\hline \multirow{2}{*}{ UTI } & Yes & $24(22)$ & $68(34)$ & \multirow{2}{*}{0.54} & \multirow{2}{*}{$0.32-0.94$} & \multirow{2}{*}{0.029} \\
\hline & No & $85(78)$ & $132(66)$ & & & \\
\hline
\end{tabular}

Abbreviations: UTI, urinary tract infection; HTN, hypertension. 
Table 3. The results of multivariate logistic regression analysis for development of urinary bladder cancer (logistic regression using forward method)

\begin{tabular}{llccc}
\hline Variable & & Odds ratio & Cl & P value \\
\hline Occupation & Yes & 2.30 & $0.12-0.88$ & 0.001 \\
& No & & & \\
& No & 1 & - & - \\
Smoking & $\mathrm{P} / \mathrm{Y} \leq 11$ & 0.10 & $0.035-0.31$ & $<0.001$ \\
& $\mathrm{P} / \mathrm{Y}=11-20$ & 0.29 & $0.09-0.94$ & 0.039 \\
& $\mathrm{P} / \mathrm{Y} \geq 21$ & 7.91 & $2.30-27.18$ & 0.001 \\
& $1-4$ & 1 & & - \\
Fluid intake & $5-8$ & 7.68 & $2.91-20.27$ & $<0.001$ \\
(glasses) & $<11$ & 5.31 & $1.66-16.96$ & 0.005 \\
& Yes & & & \\
Gender & No & 0.17 & $0.063-0.50$ & 0.001 \\
& Yes & & & \\
Pickle use & No & 3.20 & $1.37-7.47$ & 0.007 \\
\hline
\end{tabular}

incidence and early treatment with antibiotics had reduced the risk of urinary bladder cancer (10). In the present study, the association between UTI and cancer type of urinary bladder and adenocarcinoma was significantly correlated with the reduction of urinary bladder cancer. However, further studies should be conducted in this regard by larger samples.

A study by Bai et al in China showed that the intake of more fluids in Asian peoples has a protective effect on urinary bladder cancer, there are a few studies however on this subject (5). In the present study, the intake of fluids was associated with a reduction in the risk of urinary bladder malignancy. A study by Cantiello et al found that type II diabetes was ineffective in the risk of urinary bladder cancer, and there was no relationship between obesity and developing urinary bladder cancer, however further studies were needed (11). In this study, there was no significant relationship between the effect of diabetes and urinary bladder cancer, while no significant association between BMI and urinary bladder cancer was found too. A study by Radosavljevic et al in Serbia revealed that the consumption of greasy and pickled vegetables was a risk factor for urinary bladder cancer (12). In the current study, the use of pickles as a risk factor for the incidence of urinary bladder cancer was significantly associated with increased risk.

\section{Conclusion}

According to the results, it seems that the risk factors of cigarette smoking, male gender, high-risk occupation, the use of pickles and low-intake of water are associated with urinary bladder cancer. It should be noted that in our population, the risk of urinary bladder cancer was raised with the increase of smoking.
Limitations of the study

The study was single-center and conducted on a relatively low-sample size. Consequently, randomized controlled trials are necessary to examine the effects of smoking and other carcinogens of urinary bladder cancer.

\section{Acknowledgments}

The abstract of this study was presented as a poster by Yasamin Pouladi in the Third Congress of Nephrology and Urology, Iran (http://www.icnu.ir). The authors of the paper express their sincere gratitude to deputy research of Urmia University of Medical Sciences and all patients who participated in this study.

\section{Authors' contribution}

AT designed the experiment. YP and RG supervised the project. RG and AT involved in collecting data. All authors discussed the results and commend on the final manuscript.

\section{Conflicts of interest}

The authors declare no conflict of interest.

\section{Ethical considerations}

Ethical issues (including plagiarism, double publication) have been completely observed by the authors. This article does not contain any studies with animals performed by any of the authors.

\section{Funding/Support}

This study was the result of a thesis of Urmia University of Medical Sciences (\#94-01-40-2029), which supported by Urmia University of Medical Sciences.

\section{References}

1. Sell V, Ettala O, Perez IM, Järvinen R, Pekkarinen T, Vaarala $\mathrm{M}$, et al. Symptoms and diagnostic delays in bladder cancer with high risk of recurrence: results from a prospective FinnBladder 9 trial. World J Urol. 2019:1-7. doi: 10.1007/ s00345-019-02841-4.

2. Miyazaki J, Nishiyama H. Epidemiology of urothelial carcinoma. Int J Urol. 2017;24:730-4. doi: 10.1111/iju.13376

3. Alzaidi MA, Arab HA, Amanpour S, Shirkoohi R, Muhammadnejad S, Sasani F. Opium consumption and the incidence of cancer: does opium account as an emerging risk factor for gastrointestinal cancer? J Gastrointest Cancer. 2018; 49:172-80. doi: 10.1007/s12029-017-0050-7.

4. Wyszynski A, Tanyos SA, Rees JR, Marsit CJ, Kelsey KT, Schned AR, et al. Body mass and smoking are modifiable risk factors for recurrent bladder cancer. Cancer. 2014;120:408-14. doi: 10.1002/cncr.28394

5. Bai Y, Yuan H, Li J, Tang Y, Pu C, Han P. Relationship between bladder cancer and total fluid intake: a metaanalysis of epidemiological evidence. World J Surg Oncol. 2014;12:223. doi: 10.1186/1477-7819-12-223.

6. Antoni S, Ferlay J, Soerjomataram I, Znaor A, Jemal A, Bray F. Bladder cancer incidence and mortality: a global overview and recent trends. Euro Urol. 2017;71:96-108. doi: 
10.1016/j.eururo.2016.06.010

7. Weistenhofer W, Blaszkewicz M, Bolt HM, Golka K. $\mathrm{N}$-acetyltransferase-2 and medical history in bladder cancer cases with a suspected occupational disease (BK 1301) in Germany. Environ Health Toxical Part A. 2008;71:906-10. doi: 10.1080/15287390801988681

8. Al-Zalabani AH, Stewart KF, Wesselius A, Schols AM, Zeegers MP. Modifiable risk factors for the prevention of bladder cancer: a systematic review of meta-analyses. Euro J Epidemiol. 2016;31:811-51. doi: 10.1007/s10654-0160138-6

9. Harling M, Schablon A, Schedlbauer G, Dulon M, Nienhaus A. Bladder cancer among hairdressers: a meta-analysis. Occup Environ Med. 2010;67(5):351-8. doi: 10.1136/ oem.2009.050195.

Copyright (C) 2019 The Author(s); Published by Nickan Research Institute. This is an open-access article distributed under the terms of the Creative Commons Attribution License (http://creativecommons.org/licenses/by/4.0), which permits unrestricted use, distribution, and reproduction in any medium, provided the original work is properly cited. 